\title{
Ozone Contamination in Aircraft Cabins: Results from GASP Data and Analyses
}

J. D. Holdeman

Lewis Research Center

Cleveland, Ohio

and

G. D. Nastrom

Control Data Corporation

Minneapolis, Minnesota

Prepared for the Nineteenth Aerospace Sciences Meeting sponsored by the American Institute of Aeronautics and Astronautics

St. Louis, Missouri, January 12-15, 1981 
OZONE CONTAMINATION IN AIRCRAFT CABINS: RESULTS FROM GASP DATA AND ANALYSES

James $D$ Holdeman*

NASA Lewis Research Center. Cleveland, Ohio

and

Gregory D Nastrom **

Control Data Corp. Minneapolis, Minn.

\begin{abstract}
This paper reviews results from the NASA Global Atmospheric Sampling Program (GASP) pertaining to the problem of ozone contamination in commercial airplane cabins. Specifically analyses of GASP data have: l). conflrmed the occurrence of high ozone levels in aircraft cabins and documented the ratio of ozone inside and outside the cabins of two B747 airliners, including the effects of air conditioning modifications on that ratio; 2). better defined ambient ozone climatology at commercial airplane cruise altitudes, including tabulation of encounter frequency data which were not available before GASP and 3 ). outlined procedures for estimating the frequency of flights encountering high cabin ozone levels using climatological ambient ozone data, and verified these procedures against cabin measurements.
\end{abstract}

\section{Introduction}

Measurements of the ozone con centration in the cabins of two commercially operated Boeing 747 airliners were routinely made from March 1977 to June 1979 as part of the NASA Global Atmospheric Sampling Program (GASP). The measurements were taken in response to the concern of the publicl, 2 and the government $3-5$ because of reports attributing illnesses of some people on long duration flights to excessive ozone exposure.

A brief measurements campaign in the early 1960 s established that the ozone injested by aircraft operating in the stratosphere is only partially destroyed by the compression-ventilation system, so that cabin ozone levels may increase above levels

Index categories: Cabin Environment, Crew Training, and Life support; Flight Operations; Safety.

* Aerospace Engineer, Combustion and Pollution Research Branch.

Member AIAA

* * Research Meteorologist, Present Address, NOAA/Aeronamy Laboratory, Boulder, Colorado. commonly found in the troposphere. Until recently, however, available measurements were insufficient to determine adequately the relationship between cabin and ambient (atmospheric) ozone levels, and no tests had been made to determine the effect that modifications to the aircraft ventilation system might have on ozone amounts in the cabin. The addition of the cabin ozone measurement capability to the GASP system on a 747-100 and $747 \mathrm{SP}$ provided simultaneous cabin and ambient ozone data from flights of varying duration, altitude, and season. Four cabin ozone reduction methods were tested during the data collection period on the $747 \mathrm{SP}$.

The purpose of this paper is to present selected examples of the ozone data thus collected and a statistical summary of the results for over 20,000 simultaneous cabin and ambient ozone observations made from March 1977 to October 1978. Also, the results of the different ozone reduction methods used on the 747SP are discussed. Complete presentation of all GASP cabin ozone data used here is given in References 7 and 8 .

In addition to the simultaneous cabin and ambient ozone measurements, GASP acquired over 100,000 ambient ozone observations around the world at airliner cruise altitudes from March 1975 to June 1979. These have added considerably to the climatological data base over what was previously available from ozonesondes, and have provided data in geographical regions where none were previously extant.

One aspect of the cabin ozone problem which will be addressed herein is the question of how frequently commercial airliners encounter given ambient ozone levels. The GASP data are uniquely appropriate for addressing this question as they were obtained in routine commercial service and provide encounter frequencies directly.

\section{Ozone Measurements System}

GASP was initiated by NASA in December 1974 to collect data on atmospheric constituents using instruments place on board commercial airliners. Due to the size of the GASP

This paper is dectared a work of the U.S. 
instrument package, only B747 air planes could be used. Both the am bient and cabin ozone were measured by an ultraviolet spectrophotometer with an operating range of $0.003-20$ ppmv (parts per million by volume) and with a sensitivity of 0.003 ppmv. Air from outside the aircraft was sampled by a special external probe extending beyond the boundary layer near the nose of the aircraft. The cabin air inlet was located about $1.5 \mathrm{~m}$ above the floor in the forward compartment of the 747, on the outside wall of the circular staircase. The GASP system is completely automated, with all data recorded on tape. The ozone readings updated every 20 sec., although they were normally recorded only every 5 min. During the data processing, the tropopause pressure height corresponding to each ozone measurement is time and space interpolated from the $\mathrm{Na}$ tional Meteorological Center (NMC) tropopause analyses and merged with the GASP data. Other details on the GASP cabin and ambient ozone measurements can be found elsewhere $9-12$.

\section{Ozone Variations}

In the atmosphere the local ozone concentration varies with both space and time. Mean ambient ozone levels are typically less than 0.1 ppmv in the troposphere and greater than 0.2 ppmv in the stratosphere as seen in Figure 1. In this and subsequent figures, the shaded area shows $t 1$ standard deviation from the GAS $\bar{P}$ mean in each interval. The GASP means are in excelient agreement with the distribution from the U. S. Standard Atmosphere (Ref. 13). The mean ambient ozone varies with latitude, increasing from the equator poleward (Fig. 2), and with season, having maximum values during spring (Fig. 3). The GASP mean values in Figs. 2 \& 3 are from Reference 14. Ozonesonde mean values, from Reference 15, are also shown for comparison. However, superimposed on these variations of the mean values are the sometimes very large variations with synoptic weather systems. Since these variations result in mixed tropospheric and stratospheric data at a constant flight level, they are a primary cause of the very large standard deviations seen in Figures 2 and 3 . The point is that as the cabin air is obtained from outside, cabin ozone levels might be expected to depend upon all of these factors.

In addition, the cabin ozone level will depend upon how much ozone is destroyed in the ventilation system. The ozone retention ratio (cabin to ambient) can be expected to vary between aircraft types and will further vary if the ventilation system of an aircraft is modified. Each of these points will be shown by comparing the statistical results of data from the 747-100 and the unmodified and modified configurations of the $747 \mathrm{SP}$. Before discussing the statistical results, we will present data from a typical GASP flight as an introduction to the type of records upon which the statistics are based.

\section{Simultaneous Measurements}

Figure 4 shows the ambient and cabin ozone data (middle panel) along a flight of the United 747-100 from San Francisco (SFO) to New York (JFK) on March 12, 1978. Also shown are the aircraft latitude and flight level (upper panel), and the ratio of cabin to ambient ozone (lower panel) all as a function of flight time. In this and the following figure, data are connected by solid lines except when gaps in the data exceed $10 \mathrm{~min}$. duration (ratio values are plotted only when ambient ozone exceeds 0.1 ppmv). The label flight level (hundreds of feet) is used to signal that standard atmosphere equivalent pressure altitudes, rather than true geometric altitudes, are the coordinate.

An important point to note in Figure 4 is that the cabin ozone curve follows the ambient ozone curve (the mean ratio on this flight was 0.43 , and the correlation coefficient was $0.72)$. For all observations taken on the B747-100 to October 1978, the mean ratio of cabin to ambient ozone (retention ratio) was 0.381 . The correlation coefficient for these measurements was 0.85 , and may have been even greater, except there is time lag of a few minutes while outside air is being mixed with the air in the cabin.

Table I summarizes the ozone retention ratio data for both GASP equipped aircraft. As we are concerned only about those times when ozone may be a problem, only those observations when the ambient ozone amount was above 0.1 ppmv were used when compiling Table 1 . Because of ventilation system modifications or changed operating procedures, the data from the 747SP are divided among the following categories; 1). unmodified, 2). unmodified with 15th stage compressor bleed, 3). increased air recirculation, 4). increased air recirculation with 15 th stage compressor bleed, and 5). charcoal filter. There may be factors other than those listed which influence the retention ratio from flight to flight or even within a flight, such as load factor or flight duration, 16 but these are not considered here.

In Table 1 , the retention ratio for the unmodified 747SP (May - June 1977 ) is 0.825 which is more than 
double the mean value from ali measurements on the 747-100. These two moan valurs are different. with a statistical significance of greater than 99 percent, which clearly indicates that retention ratios cannot be extrapolated among aircraft types with much certainty.

Four different methods were used to reduce the cabin ozone on the $747 \mathrm{SP}$. Increased surface contact was promoted by increased recirculation of the cabin air, which caused a 33 percent decrease in the mean retention ratio (Table 1). Note, however, that despite the air recirculation, the mean ratio for the $747 \mathrm{SP}$ aircraft was still higher than that for the 747-100 aircraft.

Another ozone destruction method was the use of 15 th stage compressor bleed for the cabin air, rather than the normal 8 th stage compressor bleed, The higher temperature (340$480^{\circ} \mathrm{C}$ ) associated with the 15 th stage caused much more of the ozone to dissociate before entering the cabin. Fifteenth stage bleed was used intermittently both on the unmodified aircraft and atter the air recirculation modification, and the results are listed separately in Table 1 . The use of high temperature bleed caused about a 658 decrease in the retention ratio. Examples of flight data with l5th stage bleed in use are given in References 7 and 17 .

On August 6,1977 , a charcoal.

filter was installed in the ventilation system of the $747 \mathrm{SP}$ aircraft. This filter was very effective in destroying ozone entering the cabin as illustrated by the flight record in Fig. 5 and summarized statistically in Table 1. For all observations from August 6, 1977 to October 4, 1978 using the charcoal filter, the mean ratio was 0.081 . This is a $90 \%$ decrease from the mean of the May - June measurements on the original configuration of the SP airplane.

Weekly-averaged retention ratio data from this airplane are shown in Fig. 6. Data from May 12 to August 6, 1977 are separated according to whether or not high temperature bleed was in use. The decrease in the ratio of cabin to ambient ozone after the filter installation is dramatic, but note that there appears to be an annual cycle in this ratio, with highest ratios during spring when ambient levels are highest (c.f. Fig. 3). This suggests a proportionality with ambient ozone, as would be expected if surface contact were the dominant mechanism destroying ozone in the cabin air system 18, 19. Fig. 7 shows the mean retention ratio as a function of ambient ozone level for both GASP equipped 747 's. The anticipated increase in retention ratio with ambient ozone concentration for the charcoal-filter equipped SP is confirmed for ambient levels from . 2 to .7 ppmv. Above .7 ppmv the mean retention ratio is nearly constant, but this may not be statistically significant as the number of observations falis off rapidly. Note that, in contrast to the SP, no statistically significant trend is evident in the 747-100 data (see also Ref. 20).

\section{On Using Atmospheric Ozone Climatological Data To Estimate Cabin Ozone Encounter Frequencies}

About a year ago, the Federal Aviation Regulations were amended 5 to require carriers operating trans port category airplanes above FLl 80 to demonstrate to the FAA that the ozone concentration inside the cabin will not exceed. 25 ppmv, sea-level-equivalent* (ppmv SLE) at any time (the maximum value limit); and that a timeweighted average value of 0.1 ppmv SLE will not be exceeded on scheduled flight segments of more than 4 hours. Clearly, the best way to show compliance with the rule is with cabin, or better yet simuitaneous cabin and ambient, measurements such as those discussed in the previous section. However, if these data are not available or obtainable, other methods have been show to yield reasonable estimates of ozone encounters 20. One of these procedures is the use of atmospheric ozone climatological data, in conjunction with a known or assumed retention ratio, to show "with a statistical confidence of least 84815,21 that the cabin ozone limits will not be exceeded.

This section presents an example of how tabulated ambient ozone data might be used to investigate compliance with the rules. Our procedure differs from the one in the FAA Advisory Circular 21 in that 1 ). we will use GASP empirical ambient ozone encounter probability data in preference to inferring probabilities from available ozonesonde statistics, and 2). our procedure for estimating the probability of encountering the maximum value limit at any time during a flight differs from that given in Reference 21. Therefore, anyone making this type of calculation for the purpose of demonstrating compliance should refer to Reference $2 I$

* The statement of the rule in units of sea-level-equivalent ppmv (ppmv SLE) is equivalent to specifying $1 \mathrm{im}-$ its on ozone density $\left(\mathrm{e} . \mathrm{g} ., \mathrm{g} / \mathrm{m}^{3}\right)$. For a constant ozone density, the allowable true volume fraction (e.g., ppmv) in the cabin will vary inversely with cabin pressure. 
and contact the rAA regarding acceptabie data and procedures

\section{Problem}

How frequently would a B747 $100 \mathrm{fly}$ ing over the contiguous United States at FL370 in the spring encounter cabin ozone levels in excess of the prescribed limits?

\section{Solution}

The mean retention ratio for this type of aircraft is found in Table 1 to be 0381 The ratio of the density of the cabin air corresponding to these measurements to the density of sea level air at $25^{\circ} \mathrm{C}$ is 08 There fore the maximum cabin ozone limit of

25 ppmy SLE corresponds $2 i$ to an ambient ozone level of

$$
(25) /(18)(381),=082 \mathrm{ppmv}
$$

and the time weighted average cabin ozone limit of $\perp$ ppmv SLE corre sponds $2 i$ for an average transcon tinental flight assuming a $5 \mathrm{hr}$ scheduied time of which $1 \mathrm{hr}$. is taxi and ascent and descent) to an ambient time-weighted-average level of

$$
(.1) /((8)(381))(5 / 4)=0.41 \text { ppmv }
$$

Time-weighted-average limit. It was shown in Reference 20 that the probability of the mean ozone level at cruise exceeding a given value can be approximated by the probability that any observation exceeds the same

level. The solution given here will fol low procedure I A 3 in Reference 20 , except that we will use the tabulated median 84 th percentile and 98 th per centile values from Ref 14 as a four point approximation to the ozone cumu lative frequency distribution (cfd) since the data used in this example are tabulated by $10^{\circ}$ latitude inter vals, we will combine data from $30^{\circ}$ to $40^{\circ} \mathrm{N}$ and $40^{\circ}$ to $500 \mathrm{~N}$ at 750 to $1200 \mathrm{~W}$ longitude as a reasonable geographical approximation of the contiguous United States. Alternatively, this combination can be viewed as an interpolation to $40^{\circ} \mathrm{N}$, which would be the appropriate latitude to use in estimating the frequency of high ozone encounters on most transcontinental flights.

The separate four-point cfd's for $30^{\circ}$ to $40^{\circ} \mathrm{N}$ and $40^{\circ}$ to $50^{\circ} \mathrm{N}$ are shown in part a of figure 8 . Since the 84 th percentils values are greater than $0.4 \mathrm{l}$ ppmv in both lati tude zones, the probability of encountering ambient ozone above 0.41 ppmv will be greater than 16 percent. If necessary, we can obtain a numerical estimate as follows: for $30^{\circ}$ to $40^{\circ} \mathrm{N}$ we find that the probability of encountering ambient ozone greater than 0.41 ppmv is 21.5 percent, and for $40^{\circ}$ to $50^{\circ} \mathrm{N}$ the corresponding probability is 29.7 percent. Weighting the regions equally (the number of observations is approximately the same in both regions) gives a probability of 25.5 percent that the cruise-mean ambient ozone level will exceed 0.41 ppmv. The composite cfd for $40^{\circ} \mathrm{N}$ interpolated from the Reference 14 tabulations is shown in Fig. $8 \mathrm{~b}$.

Note that these estimates are based on empiricial encounter frequency data and do not require any assumption of the frequency distribution of the ozone levels in the selected grid. In contrast to this, use of previous climatological tabulations which give mean and standard deviation values requires either an explicit or implicit assumption of the form of this distribution. Specifically, direct use of the tabulations in Reference 15 includes the assumption that the distribution is normal (Gaussian) in conflict with the frequency distributions shown in figure 7 and Ref. 20. To illustrate this point, we have shown as a dashed line in Fig $8 \mathrm{~b}$ the cfd for the example dataset which one would calculate from the mean and standard deviation assuming a Gaussian distribution. In this particular example, encounter probability estimates made using this assumption would be reasonable, as the curves cross in the vicinity of the solution point but this is probably fortuitous. Over the entire range of ozone encountered, the empirical method provides more reliable estimates than procedures requiring an assumed frequency distribution. Therefore, when empirical data are available, we feel they should be used in preference to tabulations which require that the form of the frequency distribution be assumed, either explicitly or implicitly, in order to estimate probabilities.

If we examine the flight-averaged data for a B747-100 in domestic U. S. service from March 30 to June 13, 1977 (Table IV in Ref. 20), and delete flights to and from Hawail, we find that 4 out of 18 transcontinental flights, or 22 percent, encountered average cabin ozone levels in excess of 0.1 ppmv SLE. This is in very good agreement with our estimate; however, because of synoptic variability, we should not, in general, expect calculations based on climatological data to predict exactly the frequency of encountering a given ozone level on individual flights or series of flights.

Maximum value limit. - The solution to this problem will follow procedure II-A3 in Reference 20 . In this example we first determine the probability that the ambient ozone level will exceed $0.82 \mathrm{ppmv}$ on any observation. Since 0.82 is greater 
than the tabulated 98 th percentile values in both latitude zones the probability of encountering ambient ozone greater than 82 ppmv is less than 28 at any randomly-selected time. However due to synoptic variability, uniform ambient conditions would not be expected throughout a flight, and therefore the probability of exceeding a given leve?. on any random observation is not the same as the probability of never exceeding that level throughout the flights. Following the procedure in Reference 20, we assume that the average time at cruise will be $3 \mathrm{hr}$., and that there will be two independent observations per hour. So for this example there will be six independent observations on the average duration flight. The probability of encountering one or more observations of ambient ozone greater than 0.82 ppmv is estimated tobe (see Ref. 20).

$P(k \geq 1)=100\left(1-(1-(2 / 100))^{6}\right)=11.48$

Note that this is more than 5 times greater than the probability of encountering ambient ozone above 0.82 ppmv on any observation in either iatitude zone.

The estimate above may be compared with the flight-maximum values from the Reference 20 example-case data set (again with Hawaii flights deleted) in which cabin ozone in excess of 0.25 ppmv SLE was found on $10 / 40=25$ of the flights. Note that this is slightly more than double our estimate above, and suggests that the time between independent observations may be less than $1 / 2$ hr. More importantly however, the empirical data show that the probability of encountering ambient ozone in excess of .82 ppmv on any flight is more than 10 times greater than the probability of encountering ambient ozone in excess of .82 ppmv on any random observation.

\section{$\underline{\text { Summary }}$}

The more than 100.000 GASP ambient ozone observations obtained at airliner cruise altitudes around the world from March 1975 to June 1979 have greatly increased the available atmospheric ozone data, and have provided data in previously uncovered regions. In addition, over 20,000 simultaneous cabin and ambient ozone measurements were made on two B747 airliners. These data permit a direct evaluation of the cabin ozone levels encountered, and the ratio of cabin ozone concentrations to those outside the airplane (retention ratio). Two examples of simultaneous measurements of the cabin and ambient ozone along commercial air routes have been given, along with statistical results on the effect of four ozone reduction schemes. The ozone retention ratio depends primarily upon the aircraft type and the configuration of its ventilation system: the fraction of ambient ozone retained in the cabin was found to be 0.381 for a 747-100. The retention ratio for this aircraft was 548 lower than for an "as manufactured" $747 \mathrm{SP}$. However, the ratio for the $747 \mathrm{SP}$ was reduced by 33,65 , and 90 respectively as a result of increased cabin air recirculation, use of high temperature bleed for cabin air, and installation of a charcoal filter. Note, however that whether or not a given flight will encounter high cabin ozone levels also depends upon meteorological conditions.

An example case calculation is presented to illustrate how climatological atmospheric ozone data might be used to estimate the frequency of comercial airline flights encountering high cabin ozone levels. These estimates agree favorably with cabin measurements, but it must be noted that estimates based on climatology may not predict exactly the frequency of encountering high cabin ozone on an individual flight or series of flights.

\section{Acknowledgment}

This work was supported, in part by the High Altitude Pollution Program, of the office of Environment and Energy, Federal Aviation Administration through Interagency Agreement DOT-FA78WAI-893.

\section{References}

1. Carley, W. M., "A New Danger Aloft for Air Travelers; Ozone-Gas Sickness," The Wall street Journal, May 5, 1977, p. 1.

2. Carley, W. M., "Mal d'Air: Ozone Illness Returns on Some Airline Flights, and the FAA Prepares to Issue First Regulations," The Wall Street Journal March 28, 1978 , p. 40 .

3. Aircraft Cabin Ozone Contamination, Advanced Notice of Proposed Rulemaking, Federal Register, Vol. 42, Oct. 6. 1977, pp. 54427-54428.

4. Ferrarese, J. A., Airplane Cabin Ozone Contamination, Federal Register, Voi. 43, Oct. 5, 1978, pp. 46034-46027.

5. Airplane Cabin Ozone Contamination. Federal Register, Vol. 45, No. 14, Jan. 21, 1980, pp. $3880-3883$. 
;. Brabets, R. I., Hersh, C. K. and Klein, M. J. "Ozone Measurement Survey in Commercial Jet Aircraft," Journal of Aircraft, Vol. 4. Jan.-Feb. 1967, pp. 5964 .

7. Perkins, P. J., Holdeman, J. D., and Nastrom, G. D., "Simultaneous Cabin and Ambient Ozone Measurements of B747 Airplanes, Volume I" FAA-EE-79-05 (Also NASA (TM-79166), Oct. 1979 .

3. Holdeman, J. D., Briehl, D., Papathakos, L. C., Higgins, G. J., and Nastrom, G. D., Simultaneous Cabin and Ambient Ozone Measurements on Two Boeing 747 Airplanes; Volume II, FAA-EE-81-xx (Also NASA $T M-x \times x \times x)$, in review, 1981.

3. Tiefermann, M., "The Ozone Measurement System for the NASA Global Air Sampling Program; NASA iPl 451, May 1979 .

10. Holdeman, J. D., et. al., "NASA Global Atmospheric Sampling Program (GASP): Data Report for Tapes VL0010 \& VLO012." NASA TM-79061, 1979.

11. Briehl, D., Duãzinski, T. J., ana Liu, D. C., NASA Global Atmos-. pheric Sampling Program (GASP): Data Report for Tape VLoOl4". NASA TM-81579, 1980.

12. Papathakos, L. C., and Briehl, D., NASA Global Atmospheric Sampling Program (GASP): Data Report Eor TApes VLOOI5, VI0016, VL0017, VLO018, VLO019, and VL0020." NASA TM-81661, 1980.

13. U. S. Standard Atmosphere, 1976. NOAA, NASA, USAF, Washington, DC, 1976.

14. Nastrom, G. D., and Holdeman, J. D., "Tabulations of Ambient Ozone Data Obtained by GASP Airliners: March 1975 to December 1977. FAA-EE-80-43 (Also NASA TM-81528), 1980 .

15. Belmont, A. D., Wilcox, R. W. , Nastrom, G. D. , Hovland, D. N. and Dartt, D. G., "Guidelines for Flight Planning During Periods of High Ozone Occurrence," FAA-EQ-78-03, 1978 .

16. Perkins, Porter J. and Briehl, Daniel, "Simultaneous Measurements of Ozone Outside and Inside Cabins of Two B-747 Airliners and a Gates Learjet Business Jet," Technical Paper presented at Conference on Atmospheric Environment of Aerospace Systems and Applied Meteorology, AMS/AIAA, Nov, 13-16, 1978. Also NASA TM-78983.
17. Nastrom, G. D. Holdeman, J. D., and Perkins, P. J., "Measurements of Capin and Ambient Ozone on B747 Airplanes," Journal of Aircraft, Vol. 17, No. 4, April 1980, pp. 246-249.

18. Holdeman, J. D., and Lezberg, E. A., "NASA Global Atmospheric Sampling Program (GASP): Data Report for Tape VLO002," NASA TM $x-73484, I 976$.

19. McMillan, R. D., Jr., "Application of a Precision Ozone Generator in Calibration of Ozone/Oxidant Analyzers and Inlet Sample Air systems," ISA AID 72415 (61-66), 1972 .

20. Holdeman, J. D., "Procedures for Estimating the Frequency of Commercial Airline Flights Encountering High Cabin Ozone Levels, NASA TP-1560, 1979.

21. "Transport Category Airplanes Cabin Ozone Concentrations" Dept. of Transportation, FAA Advisory Circular AC 120-38, Oct. 10, 1980. 
TABLE 1 - CORRELATION BETWEEN CABIN AND AMBIENT OZONE LEVELS

Retention ratioc

\begin{tabular}{|c|c|c|c|c|c|}
\hline & $\begin{array}{c}\text { Ozone destruction } \\
\text { method }\end{array}$ & $\begin{array}{c}\text { No. of } \\
\text { individual } \\
\text { observations }\end{array}$ & Mean & $\begin{array}{l}\text { Standard } \\
\text { deviation }\end{array}$ & $\begin{array}{l}\text { Correlationd } \\
\text { coefficent }\end{array}$ \\
\hline $\begin{array}{l}\text { Boeing } \\
747-100^{a}\end{array}$ & $\begin{array}{l}\text { 1). None } \\
\text { Mar. 30, 1977-Oct. 6, } 1978\end{array}$ & 4556 & 0.381 & 0.185 & 0.85 \\
\hline $\begin{array}{l}\text { Boeing } \\
747 \mathrm{SPD}\end{array}$ & $\begin{array}{l}\text { 1). None } \\
\text { May 12-June 4, } 1977 \\
\text { 2). } 15 \text { th Stage Compressor Bleed } \\
\text { May } 12-\text { June 4, } 1977 \\
\text { 3). Modified air recirculation } \\
\text { June } 4 \text { - Aug. 6, } 1977 \\
\text { 4). } 2 \text { and } 3 \text { combined } \\
\text { June 4- Aug. 6, } 1977 \\
\text { 5). Charcoal filter } \\
\text { Aug. 6, 1977-Oct. 4, } 1978\end{array}$ & $\begin{array}{r}527 \\
123 \\
1955 \\
972 \\
12366\end{array}$ & $\begin{array}{l}0.825 \\
0.268 \\
0.552 \\
0.211 \\
0.081\end{array}$ & $\begin{array}{l}0.208 \\
0.132 \\
0.191 \\
0.109 \\
0.086\end{array}$ & $\begin{array}{l}0.87 \\
0.51 \\
0.81 \\
0.42 \\
0.71\end{array}$ \\
\hline
\end{tabular}

a Aircraft United N4711U. b Aircraft PanAm N533PA. CRatio = cabin ozone/ambient ozone. Only data where ambient 0.1 ppmv were used. d correlation of cabin with ambient ozone. 


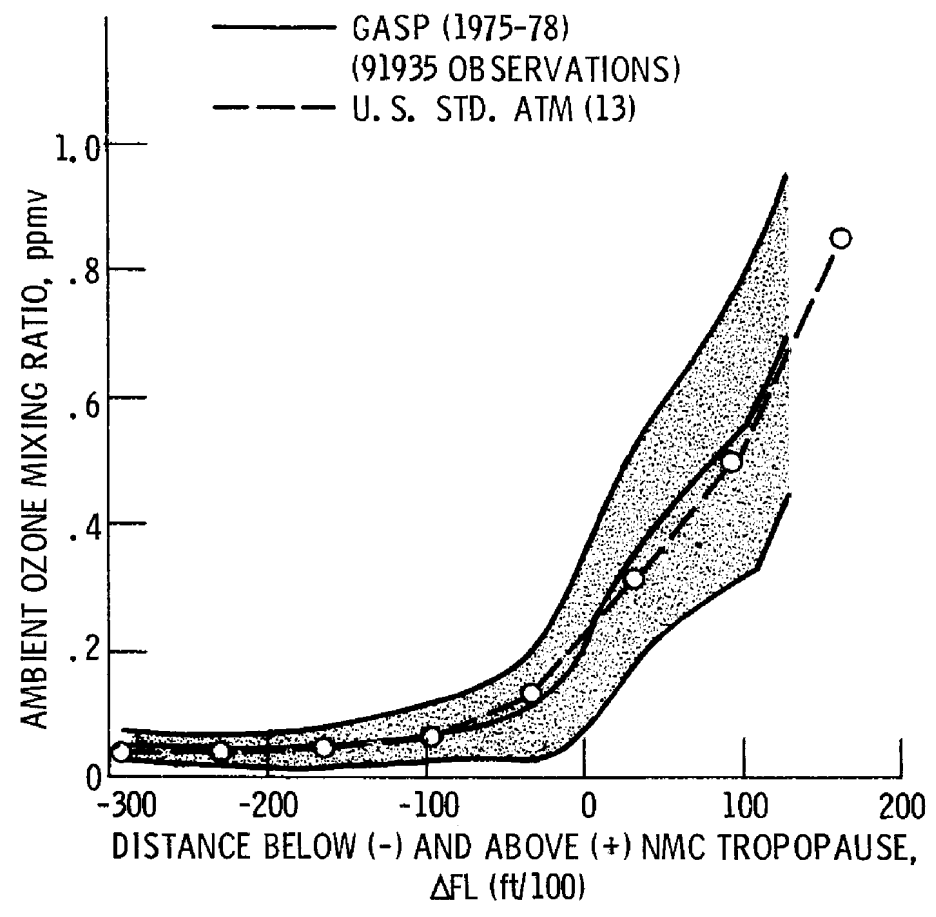

Figure 1. - Ambient ozone mixing ratios with respect to the tropopause. 


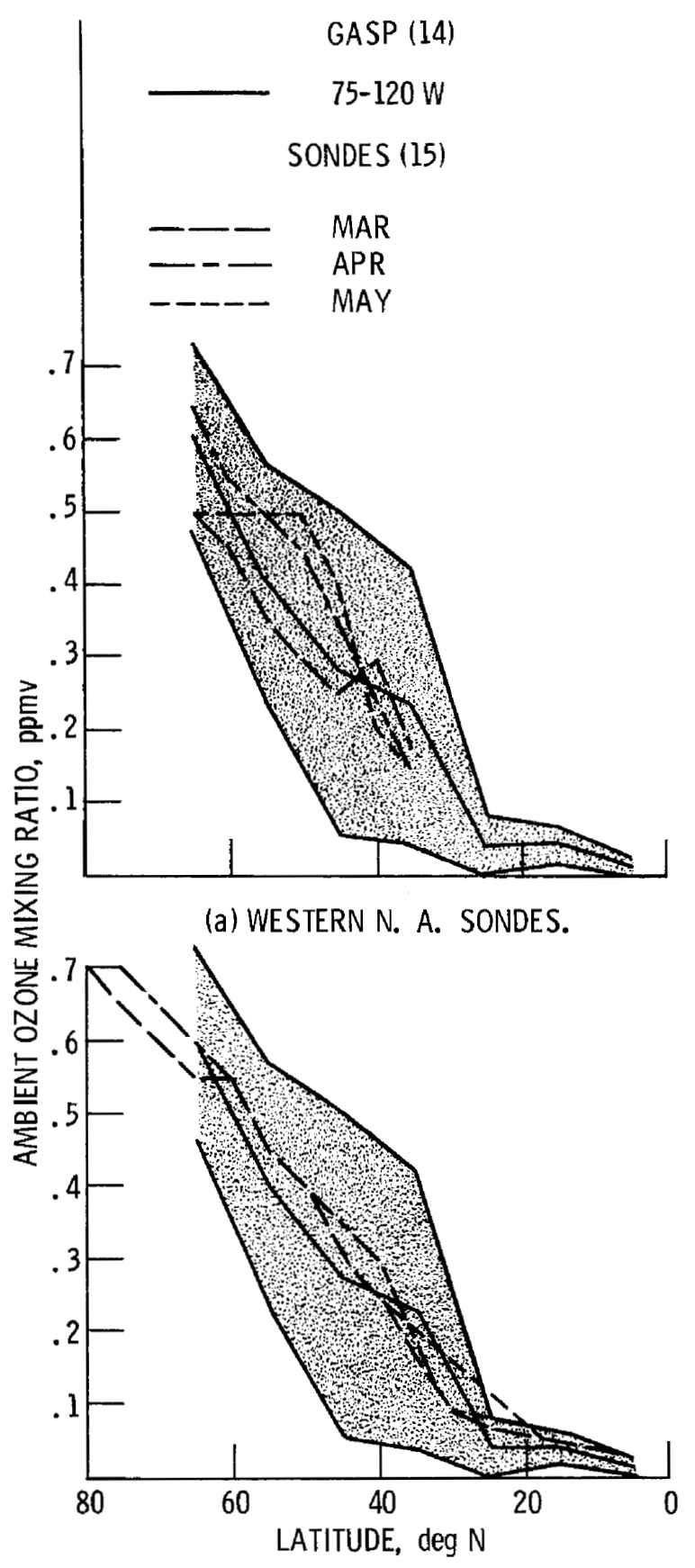

(b) EASTERN N. A. SONDES.

Figure 2. - Meridional variation of North American ambient ozone levels at FL 370 in the Spring. 


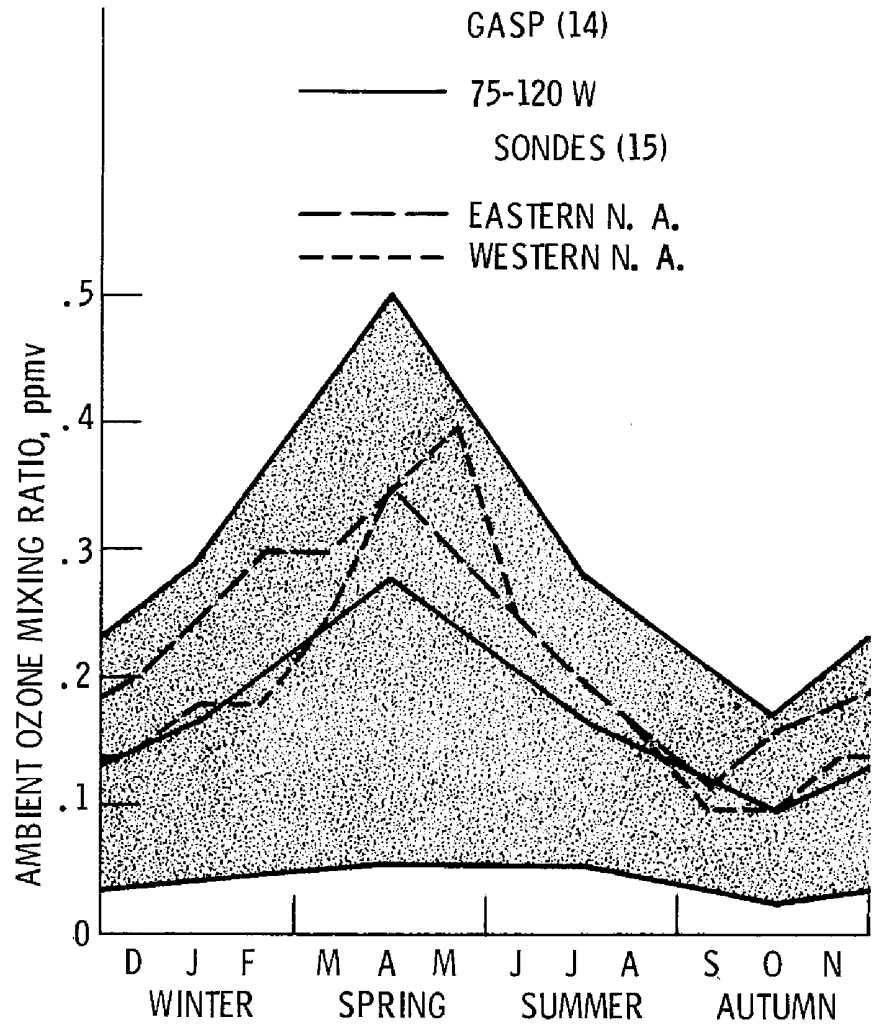

Figure 3. - Seasonal variation of mean ambient ozone at 40-50 N and FL 370 for North America.

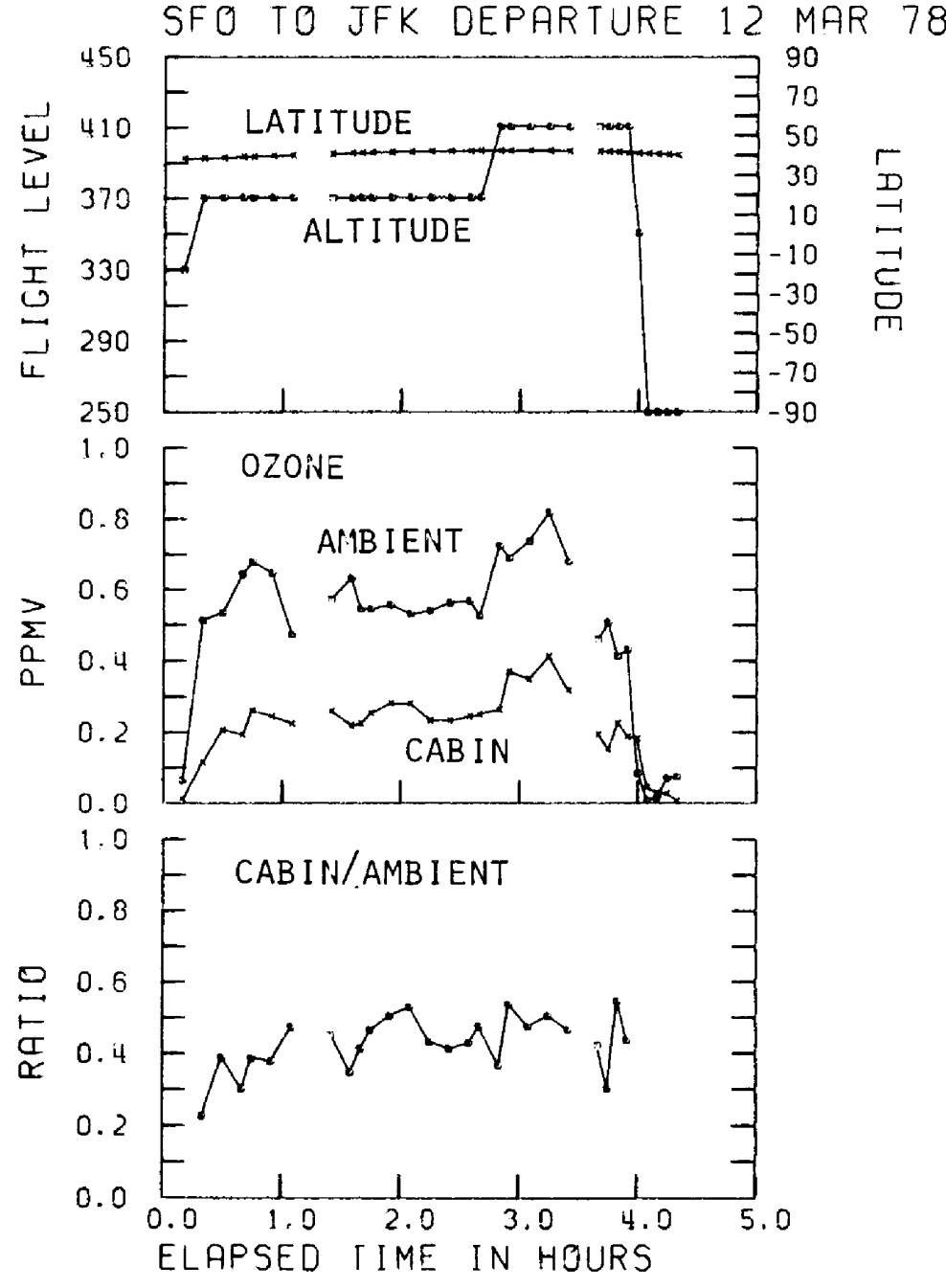

Figure 4. - Ozone flight record for B747-100 from San Francisco to New York on March 12, 1978. 


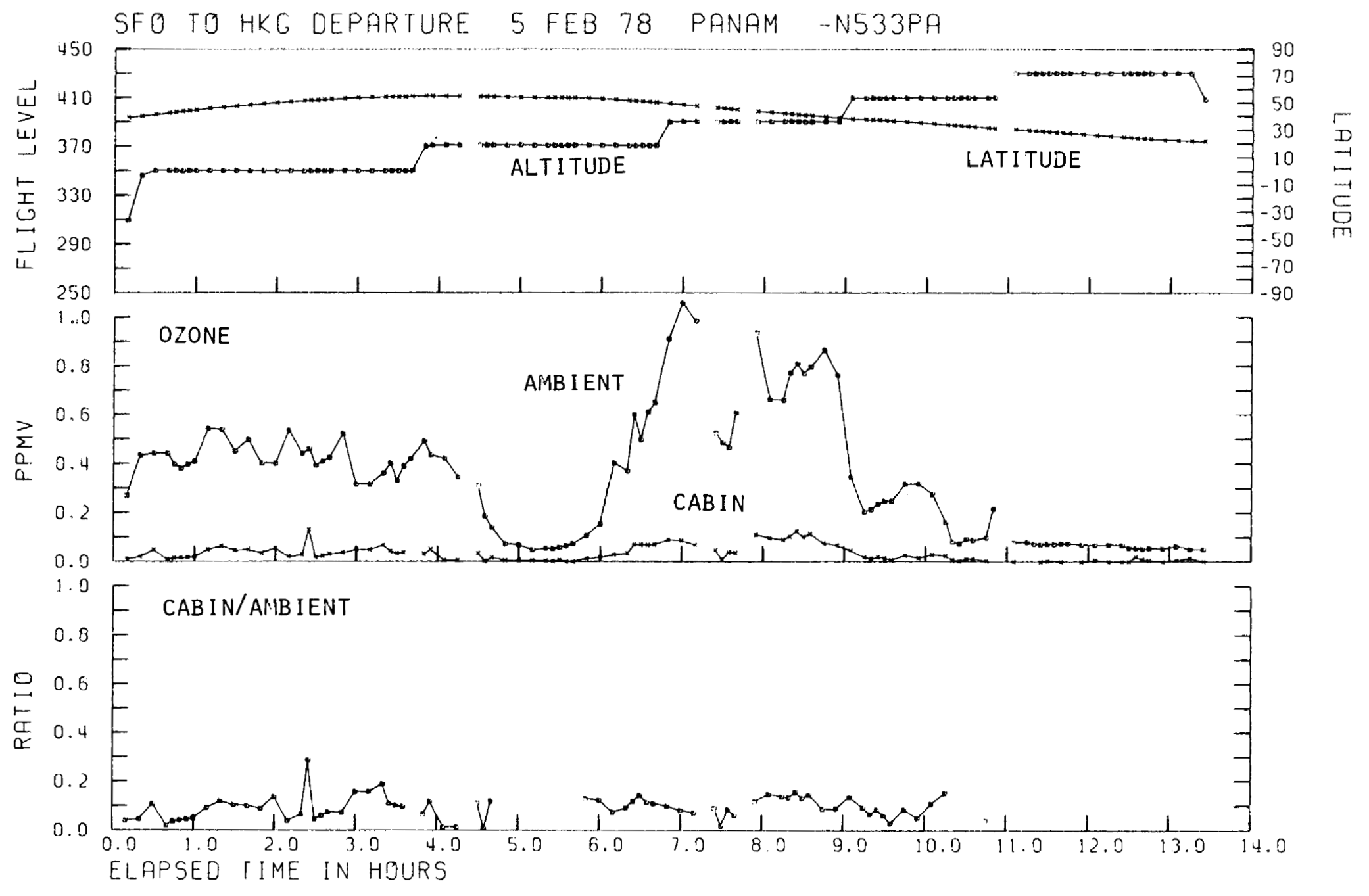

Figure 5. - Ozone flight record for B747 SP from San Francisco to Hong Kong on February 5, 1978. Charcoal filter was in use on this flight. 


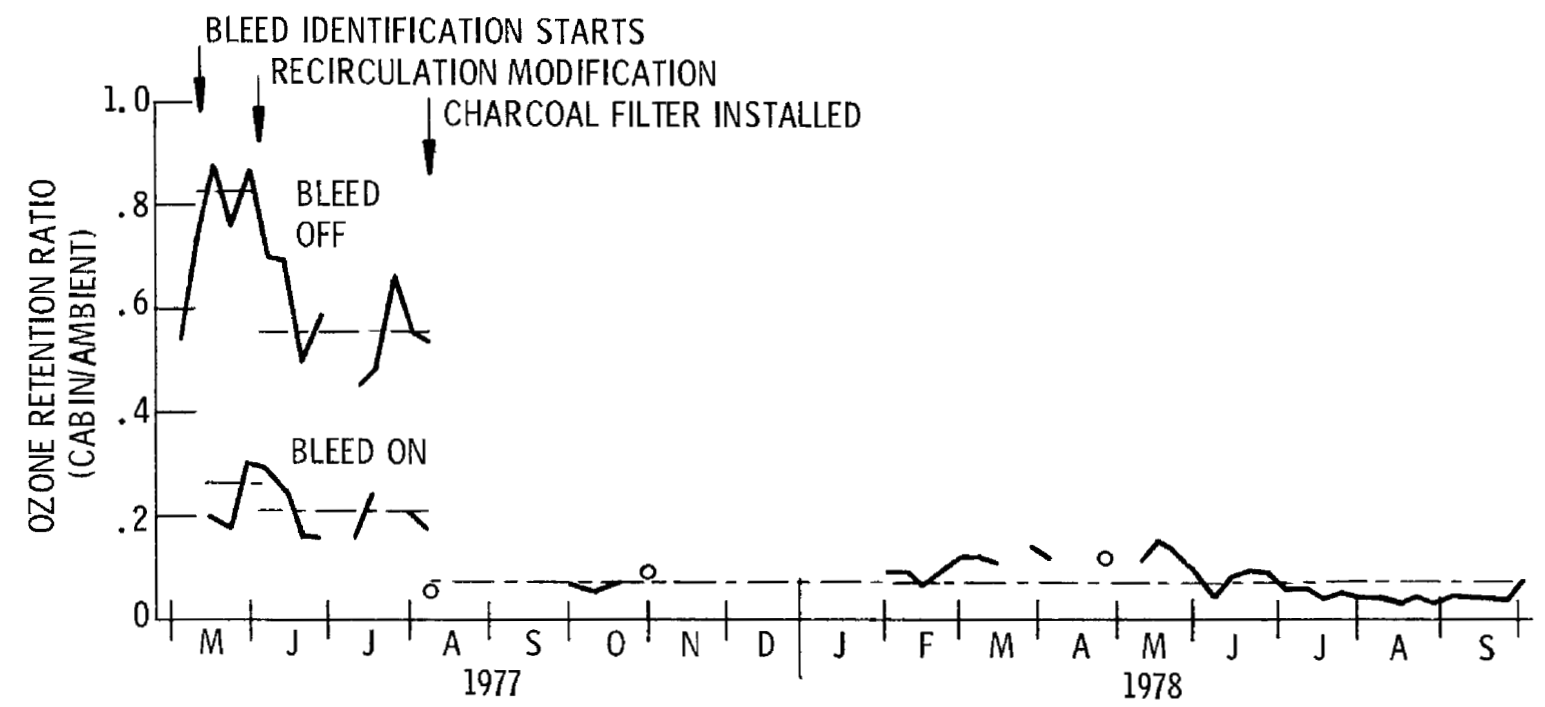

Figure 6. - Weekly-averaged retention ratio for B747 SP (N533PA); 4/26/77 to $10 / 6 / 78$.

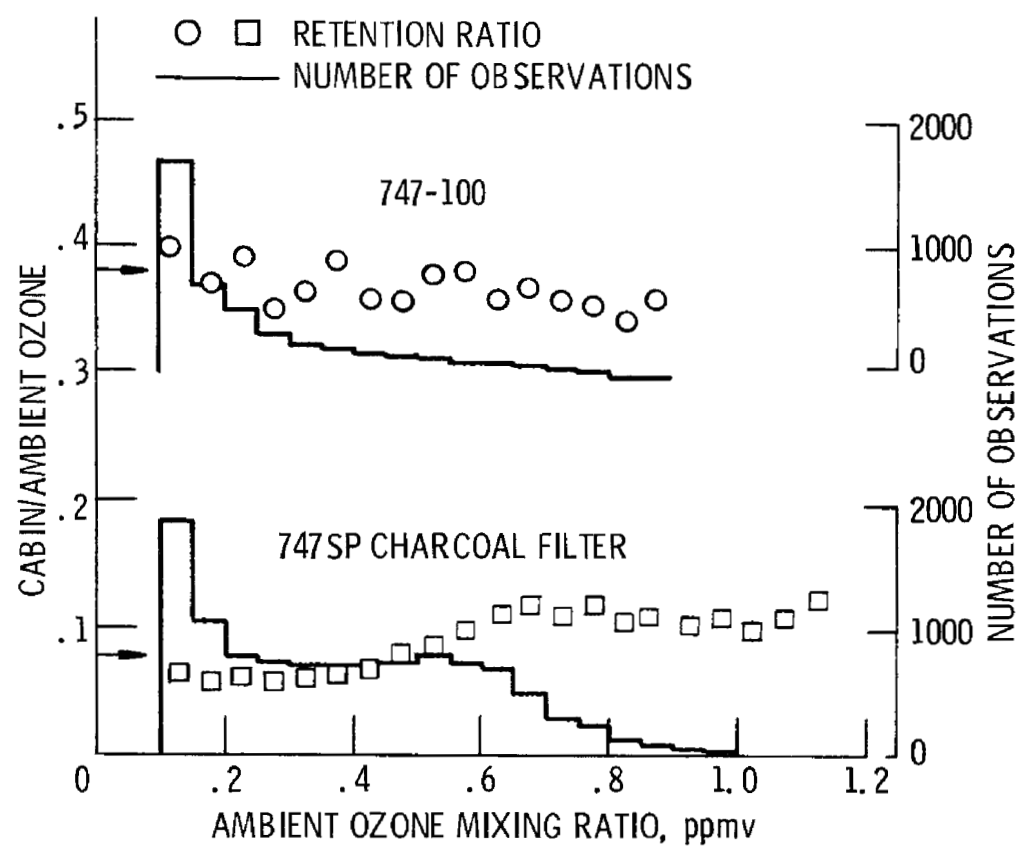

Figure 7. - Variation of retention ratio with ambient ozone level. Arrows show ensemble mean for each aircraft. 


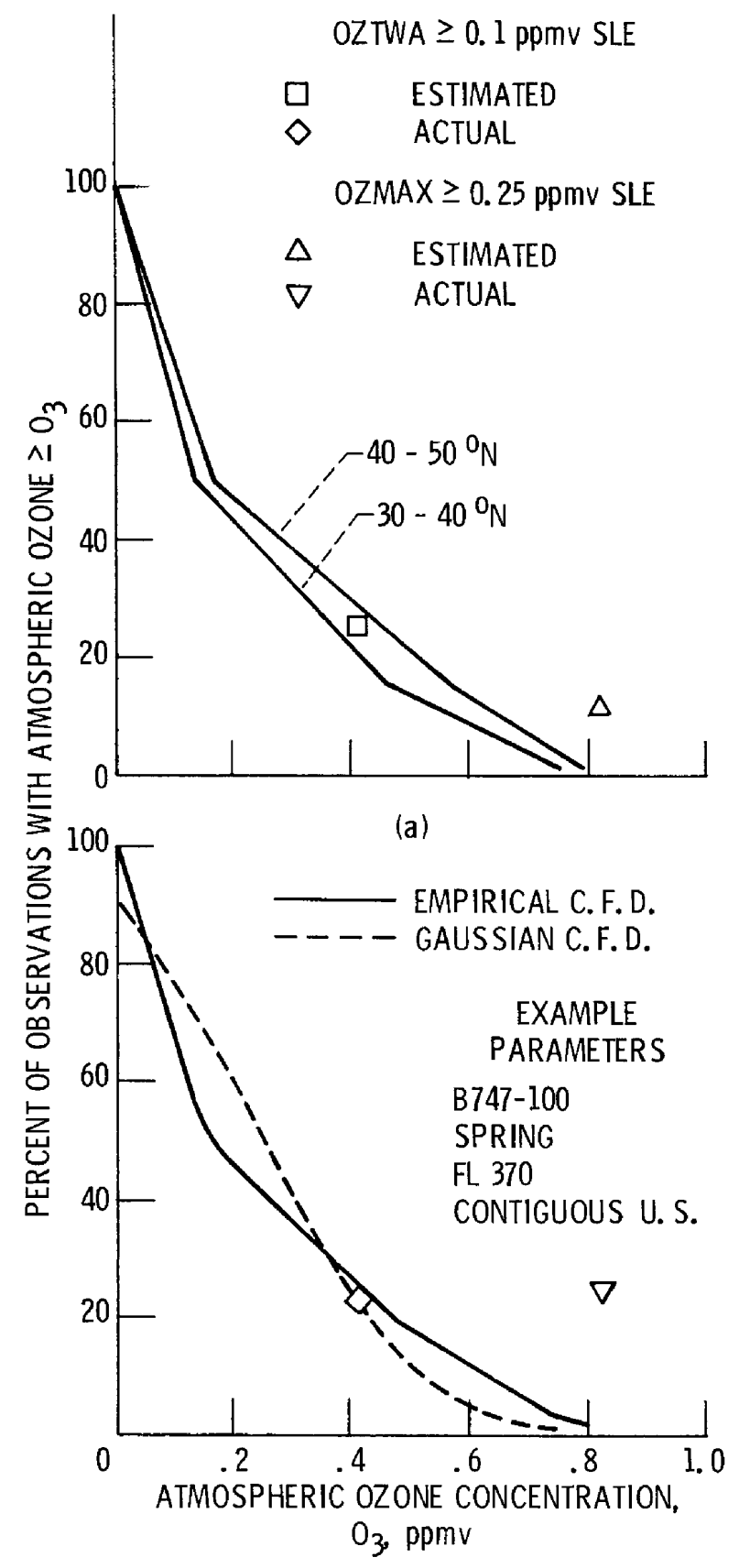

(b)

Figure 8. - Atmospheric ozone cumulative frequency distributions for spring; $75-120^{\circ} \mathrm{W}$; $30-50^{\circ} \mathrm{W}$. 


\begin{tabular}{|c|c|c|c|c|c|}
\hline & $\begin{array}{l}\text { Report No. } \\
\text { NASA TM-81671 }\end{array}$ & \multicolumn{2}{|c|}{ 2. Government Accession No. } & \multicolumn{2}{|c|}{ 3. Recipient's Catalog No. } \\
\hline \multirow[t]{2}{*}{4} & \multicolumn{3}{|l|}{ Title and Subtitle } & \multicolumn{2}{|l|}{ 5. Report Date } \\
\hline & \multicolumn{3}{|c|}{$\begin{array}{l}\text { OZONE CONTAMINATION IN AIRCRAFT CABINS: RESULTS } \\
\text { FROM GASP DATA AND ANALYSES }\end{array}$} & \multicolumn{2}{|c|}{$\begin{array}{l}\text { 6. Performing Organization Code } \\
505-08-22\end{array}$} \\
\hline \multirow{2}{*}{\multicolumn{4}{|c|}{$\begin{array}{l}\text { Author(s) } \\
\text { J. D. Holdeman, Lew is Research Center, Cleveland, Ohio and } \\
\text { G. D. Nastrom, Control Data Corp., Minneapolis, Minnesota }\end{array}$}} & \multicolumn{2}{|c|}{$\begin{array}{l}\text { 8. Performing Organization Report No. } \\
\text { E-693 }\end{array}$} \\
\hline & & & & \multirow{2}{*}{\multicolumn{2}{|c|}{ 10. Work Unit No. }} \\
\hline \multirow{3}{*}{ 9. $\mathrm{P}$} & \multicolumn{3}{|c|}{ Performing Organization Name and Address } & & \\
\hline & \multicolumn{3}{|c|}{$\begin{array}{l}\text { National Aeronautics and Space Administration } \\
\text { Lewis Research Center }\end{array}$} & \multicolumn{2}{|c|}{ 11. Contract or Grant No. } \\
\hline & \multicolumn{3}{|l|}{ Cleveland, Ohio 44135} & \multirow{2}{*}{\multicolumn{2}{|c|}{$\begin{array}{l}\text { 13. Type of Report and Period Covered } \\
\text { Technical Memorandum }\end{array}$}} \\
\hline \multirow{2}{*}{12.} & \multirow{2}{*}{\multicolumn{3}{|c|}{$\begin{array}{l}\text { Sponsoring Agency Name and Address } \\
\text { National Aeronautics and Space Administration } \\
\text { Washington, D.C. } 20546\end{array}$}} & & \\
\hline & & & & \multicolumn{2}{|c|}{ 14. Sponsoring Ayency Code } \\
\hline \multicolumn{6}{|c|}{$\begin{array}{l}\text { Supplementary Notes } \\
\text { Prepared for the Nine } \\
\text { of Aeronautics and As }\end{array}$} \\
\hline \multicolumn{6}{|c|}{$\begin{array}{l}\text { Thstract } \\
\text { This paper reviews results from the NASA Global Atmospheric Sampling Program (GASP) per- } \\
\text { taining to the problem of ozone contamination in commercial airplane cabins. Specifically, } \\
\text { analyses of GASP data have: (1) confirmed the occurrence of high ozone levels in aircraft cabins } \\
\text { and documented the ratio of ozone inside and outside the cabins of two B } 747 \text { airliners, including } \\
\text { the effects of air conditioning modifications on that ratio; (2) better defined ambient ozone } \\
\text { climatology at commercial airplane cruise altitudes, including tabulation of encounter frequency } \\
\text { data which were not available before GASP; and (3) outlined procedures for estimating the fre- } \\
\text { quency of flights encountering high cabin ozone levels using climatological ambient ozone data, } \\
\text { and verified these procedures against cabin measurements. }\end{array}$} \\
\hline 17. & $\begin{array}{l}\text { Key Words (Suggested by Autho } \\
\text { Ozone; Aircraft; Cab } \\
\text { atmospheric sampling } \\
\text { line operations; Flyin } \\
\text { environment }\end{array}$ & $\begin{array}{l}\text { FAA; Global } \\
\text { (GASP); Air- } \\
\text { nel; Cabin }\end{array}$ & $\begin{array}{l}\text { 18. Distribution State } \\
\text { Unclassified } \\
\text { STAR Categ }\end{array}$ & unlimited & \\
\hline & $\begin{array}{r}\text { Security Classif. (of this report) } \\
\text { Unclassified }\end{array}$ & $\begin{array}{r}\text { 20. Security Classif. } \\
\text { Un }\end{array}$ & $\begin{array}{l}\text { of this pagel } \\
\text { lassified }\end{array}$ & 21. No. of Pages & 22. Price \\
\hline
\end{tabular}

* For sale by the Nationa! Technical Information Service. Springfield Virginia 22161 